\title{
An integrated decision support system for Sydney Catchment Authority's water supply planning and operations
}

\author{
Harris, J.E. ${ }^{1}$, Dallimore, C. ${ }^{1}$, Loveless, A. ${ }^{1}$, Yeates, P.S. ${ }^{1}$, Maheswaren, S $^{2}$ and Kibria, G $^{2}$. \\ ${ }^{1}$ HydroNumerics Pty Ltd, Australia \\ ${ }^{2}$ Sydney Catchment Authority, Australia \\ Email: jessica.harris@,hydronumerics.com.au
}

\begin{abstract}
Australia's surface drinking water resources are commonly comprised of multiple interconnecting dams with numerous users and various water quality priorities. Managing such systems is challenging and requires innovative methods to make use of complex database systems and therefore enable optimal decision-making. Decision support systems are designed to assist decision makers, managers and operators access relevant information and make informed short and long term operational and strategic decisions through the use of data, tools and knowledge.
\end{abstract}

The Sydney Catchment Authority (SCA) is responsible for the provision of water to Sydney Water Corporation for treatment and distribution of drinking water to more than four million people in Sydney, the Blue Mountains and the Illawarra, and supply to Southern Highlands, Goulburn, and Shoalhaven communities. The water supply storages comprise $2600 \mathrm{GL}$ across 10 major (plus 6 minor) water storage dams. Of these, Lake Burragorang, the Shoalhaven Scheme and Prospect Reservoir account for $81 \%$ of the SCA water storage capacity. These systems have multiple water users and varying water quality issues. A key concern in Warragamba Dam is flood inflow dynamics and the load of catchment contaminants that can lead to outlet water quality problems, including blue-green algae. The Shoalhaven Scheme, comprised of Lake Yarrunga, Fitzroy Falls Reservoir and Wingecarribee Reservoir, is managed with respect to hydroelectric power transfers, recreational use and downstream impacts.

To manage the multiple dimensions of the storage network, a customised innovative tool is used for water supply planning and operations. The Sydney Catchment Authority Reservoir Management System (SCARMS) integrates observational data and validated catchment, hydrodynamic and water quality models into a decision support system. Five major SCA storages (Warragamba Dam, Tallowa Dam, Fitzroy Falls Dam, Wingecarribee Dam and Prospect Dam) are currently integrated into SCARMS.

SCARMS integrates an extensive supply of both real-time and historical data sources for the five storages. Real-time data sources include stream flow rates and properties, in-lake meteorology and in-lake water column temperature and water quality. Historical data sources include routine physical, chemical and biological monitoring data collected by SCA over the past 40 years. All relevant data are integrated into SCARMS and are processed, quality assessed and visualised. The data are used to drive and validate coupled three-dimensional hydrodynamics and water quality models (The Estuary, Lake and Coastal Ocean Model, ELCOM, and the Computational Aquatic Ecosystems Dynamics Model, CAEDYM). The integration of field data and numerical models allows a combination of real-time, forecast and hindcast simulations of reservoir conditions to be conducted on an ongoing basis. Collation of the field data and model scenario output in a user-friendly interface provides decision support for daily operations and long-term strategic planning. Customised reports can be generated to communicate knowledge to the range of operators, managers and selected stakeholders.

This data, model and knowledge package is housed at SCA and demonstrates successful innovations in collating a range of necessary tools into a seamlessly linked and customised decision support system for the management of large-scale water resource systems.

Keywords: $\quad$ Decision support systems, SCARMS, reservoir, three dimensional modelling. 
Harris et al., A decision support system for Sydney's water supply.

\section{INTRODUCTION}

\subsection{Decision Support Systems}

Decision support systems are designed to assist managers and operators to quickly access, view, compare and assess relevant information to make informed short and long-term operational and strategic decisions. Decision support systems draw upon various sources of data, tools and knowledge. This paper outlines a decision support system along the lines of Booty et al. (2001); that is, a specific information system that integrates a hierarchy of tools linked to form a single integrated system.

Decision support systems provide a powerful tool to optimise water resource management and allow timely warnings of adverse impacts associated with natural and anthropogenic perturbations, such as inflow events, catchment nutrient loading, destratification systems and climate change. The potential for decline in water quality can be identified in advance and action taken to minimise the impact on operational cost and ecosystem and community assets.

\subsection{Sydney Catchment Authority Reservoir Management System}

The SCA is responsible for the storage and delivery of water to it's clients. To ensure that the best quality water is selected from its storages, the SCA may select water from different reservoirs, from different offtake levels, operate destratifying equipment and monitor and analyse trends to understand water quality processes. The Sydney Catchment Authority Reservoir Management System (SCARMS), developed by the Centre for Water Research (CWR) at the University of Western Australia, in association with HydroNumerics and Sydney Catchment Authority, integrates real-time observation data from different reservoirs to provide the latest data on the condition of the supply network, and incorporates models to enhance understanding and continuously improve forecast accuracy. SCARMS has been applied to five of the SCA key water storage reservoirs, accounting for $81 \%$ of SCA's water storage capacity and so a rapid assessments of the majority of the supply network may be made to deliver the best available water quality to clients. The structure of the integrated management system is presented in Figure 1. Managers and operators (stakeholders) are able to interrogate data and model output through a graphical user interface (GUI) to provide assistance for daily management or long term strategic decisions.

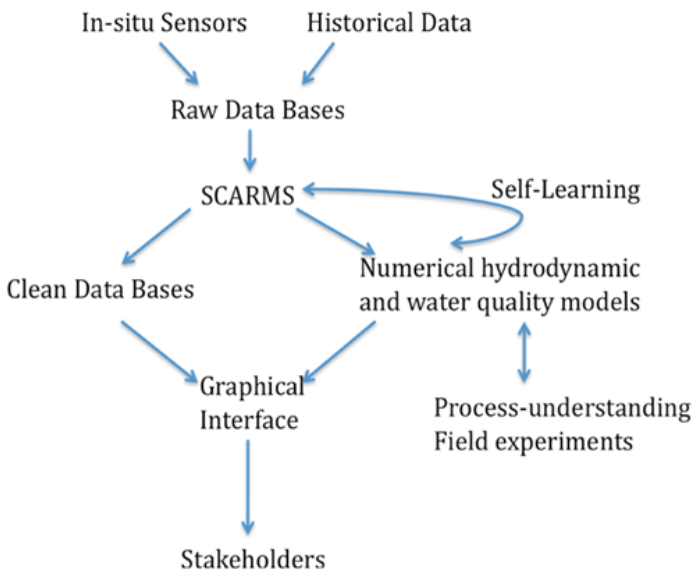

Figure 1. Flow chart presenting the Sydney Catchment Authority's Reservoir Management System (SCARMS) that provides operational and strategic guidance to water managers and planners.

\section{STUDY SITES}

The Sydney Catchment Authority is responsible for the provision of water to Sydney Water Corporation for treatment and distribution of drinking water to more than four million people in Sydney, the Blue Mountains and the Illawarra, and supply to Southern Highlands, Goulburn, and Shoalhaven communities. The water supply storages comprise $2600 \mathrm{GL}$ across 10 major (and 6 minor) water storage dams. Warragamba Dam, the Shoalhaven Scheme and Prospect Dam account for almost $81 \%$ of the SCA storage capacity.

\subsection{Lake Burragorang}

Lake Burragorang, formed by Warragamba Dam, is located about $65 \mathrm{~km}$ west of Sydney and is the largest urban water supply in Australia (2,027,000 ML), supplying approx. 70\% of Sydney's drinking water. The main channel of the lake is $20 \mathrm{~km}$ long (along the thalweg), on average $1 \mathrm{~km}$ wide and has a maximum depth of $93 \mathrm{~m}$. The water balance of the reservoir is dominated by flood events draining the Wollondilly and Cox River catchments and relatively constant outflows used for drinking water supply. 
Harris et al., A decision support system for Sydney's water supply.

A key water quality concern in Lake Burragorang is the dynamics of the flood inflows that bring potential contamination (pathogens, suspended solids and nutrients) from the catchment into the reservoir (Ewing, et al., 2004). Such inflows typically enter as dense underflows that can displace the anoxic, and potentially nutrient rich, bottom waters (hypolimnion) towards the surface of the reservoir and provide a suitable environment for algal growth. This concern was realised in August 2007 when a series of inflow events to the reservoir in June lifted the existing hypolimnion and delivered high nutrient concentrations to the photic, surface layers of the reservoir. The abundant nutrients were utilised by blue-green algae (Microcystis sp.) as the surface temperature warmed from August to October (Vilhena at al., 2010). Offtake gates operating at variable depths were adjusted and this mitigates the risks posed by toxic algal blooms to the drinking water supply scheme. However, these adjustments take half a day maximum and therefore the ability to simulate the water quality impact of a pending flood event is critical for maintaining offtake water quality (Ewing et al., 2004).

\subsection{Prospect Reservoir}

Prospect Reservoir (33,330 ML) is located on the Prospect Creek, approximately $35 \mathrm{~km}$ west of Sydney. The reservoir is roughly circular with a diameter of approximately $2 \mathrm{~km}$. Prior to 1996, the reservoir was used as a distribution reservoir for Sydney's water supply. The commissioning of the Prospect Water Filtration Plant resulted in raw water from Warragamba and Upper Nepean Reservoirs being directly transferred to the filtration plant, bypassing Prospect Reservoir. The reservoir now functions as a back-up drinking water supply in the event of water quality issues in other reservoirs. The potential for future operational change and changes to the water quality condition of Prospect Reservoir motivates the application of a decision support system and scenario modelling capability in this resource.

\subsection{The Shoalhaven System}

The Shoalhaven system, incorporating Lake Yarrunga (90,000 ML), Fitzroy Falls Reservoir (23,000 ML) and Wingecarribee Reservoir (25,900 ML), is a dual-purpose water supply and hydro-electric power generation scheme. The reservoirs are used to supply local communities and supplement other SCA storages during low inflow periods and now it is integral part of supply. Power generation involves regular exchange of stored water between Lake Yarrunga, Bendeela Pondage (a buffer storage) and Fitzroy Falls Reservoir.

Lake Yarrunga is formed by Tallowa Dam at the confluence of the Shoalhaven and Kangaroo Rivers. Water is pumped from the Kangaroo arm of the reservoir up an elevation of $127 \mathrm{~m}$ to Bendeela Pondage, and up a further 480 m elevation to Fitzroy Falls Reservoir. This water may be re-released back to Bendeela Pondage and onto Lake Yarrunga for hydro-electric power generation. Alternatively, the water may be pumped on to Wingecarribee Reservoir where it can then be transferred to Lake Burragorang and Nepean Reservoir for water supply. The majority of water for the scheme is sourced from inflow events in the Shoalhaven and Kangaroo Rivers and therefore the ability to predict water quality following such events is desirable. In addition, the transfer of water from Lake Yarrunga to Fitzroy Falls and Wingecarribee Reservoirs has the potential to influence water quality in the receiving reservoirs, further supporting the motivation for decision support and scenario modelling to manage the reservoirs. Water quality for recreation in Lake Yarrunga and water quality of downstream releases to the Shoalhaven Estuary are also of interest.

\section{METHODOLOGY}

\subsection{Data Sources}

SCARMS incorporates real-time data collected by SCA instrumentation as well as historic data from in-situ instruments and routine monitoring programmes. The CWR Lake Diagnostic System (LDS) is an instrument for detail real-time reservoir water quality monitoring. The LDS measures variables including water column temperature (via a thermistor chain), conductivity, dissolved oxygen and chlorophyll $a$ at multiple depths, as well as meteorological parameters above the water surface. A total of six LDSs have been installed in SCA reservoirs: two in Lake Yarrunga and one each in Lake Burragorang, Prospect Reservoir, Fitzroy Falls Reservoir and Wingecarribee Reservoir. The real-time data are transmitted back to SCARMS where they are error-checked, down-sampled, gaps are filled and data are then archived. An additional six thermistor chains are also present in Lake Burragorang and the data collected are transmitted to SCARMS.

Inflow volumes, temperatures and conductivities are provided to SCARMS in real-time by telemetered river loggers located in the Wollondilly River, Cox River, Kowmung River, Nattai River, Shoalhaven River, Kangaroo River, Wildes Meadow Creek and Caalang Creek. Daily outflow volumes and screen levels from 
Harris et al., A decision support system for Sydney's water supply.

each of the reservoirs are retrieved by SCARMS from SCA databases. Historical routine monitoring data collected are also retrieved from SCA databases. In addition, data collected during regular and event based sampling using a mobile water profiling instrument can be telemetered from the field and loaded into SCARMS in near real-time.

The various data sources are available for user interrogation and graphical display via the SCARMS GUI (Figure 2). A hierarchy of data sources is available for visualisation and customised plots are also configured for efficient data visualisation.

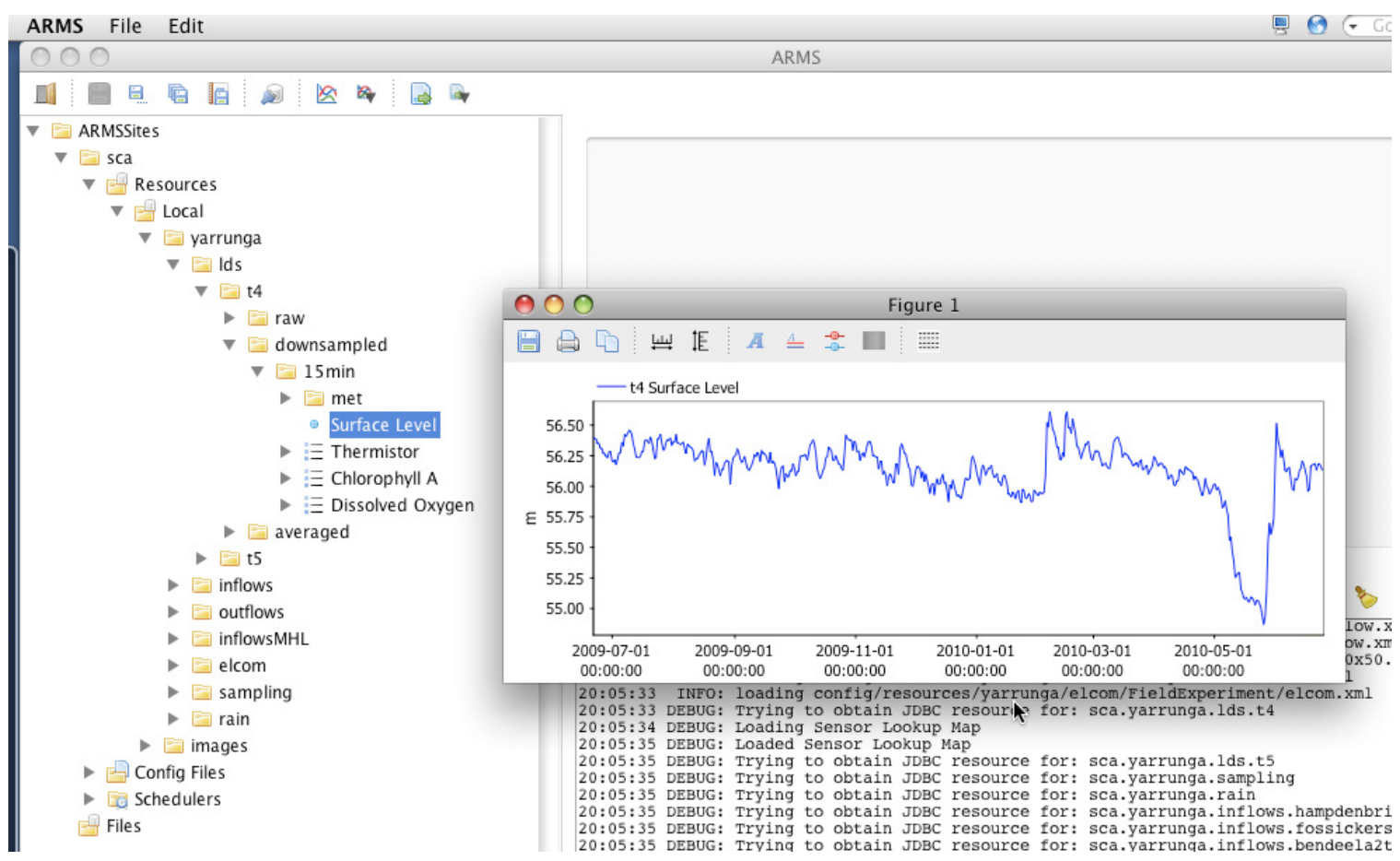

Figure 2. The SCARMS GUI displaying the hierarchy of data available and a plot generated from downsampled water level data measured at Tallowa Dam.

\subsection{Numerical Models}

Numerical models are applied in SCARMS to supplement the knowledge gained from historic and current monitoring data. The Estuary Lake and Coastal Ocean Model (ELCOM), developed by CWR, is a threedimensional hydrodynamics model designed to simulate velocity, temperature and salinity distributions in space and time. A detailed description of formulae and numerical methods can be found in Hodges et al. (2000). ELCOM solves the unsteady, viscous Navier-Stokes equations of fluid. Baroclinic and barotropic responses are modelled allowing for the simulation of stratified flows. Rotational effects, wind stresses, surface heating and transfer, inflows, outflows, and transport of salt, heat and passive scalars are also accounted. The Euler-Lagrange method for advection of momentum is applied with a conjugate-gradient solution for the free-surface height. Passive and active scalars (i.e. tracers, salinity and temperature) are advected using a conservative ULTIMATE QUICKEST discretization.

The Computational Aquatic Ecosystem Dynamic Model (CAEDYM), also developed at CWR, consists of a series of mathematical equations representing the major biogeochemical processes influencing water quality. At its most basic, CAEDYM is a set of library subroutines that contain process descriptions for primary production, secondary production, nutrient and metal cycling, and oxygen dynamics and the movement of sediment. By simulating several state variables at the species level, CAEDYM can be used to support the understanding and management of water quality in a system. CAEDYM is dynamically coupled to ELCOM with ELCOM computing all hydrodynamic processes for the water quality state variables.

ELCOM-CAEDYM has been applied to a number of reservoirs to provide detailed predictions on hydrodynamic and water quality properties (e.g., Horn et al., 2002, Hipsey et al., 2004, Chung et al., 2009). As part of a process of continual improvement, the models are configured for each of the SCA reservoirs and have been initially calibrated and validated over periods ranging from 3-months to one year to ensure the 
Harris et al., A decision support system for Sydney's water supply.

models are fit for use as a scenario forecasting tool. Data required for running the models are detailed in Table 1. CAEDYM was configured to model DO, particulate and dissolved forms of inorganic and organic nitrogen, phosphorus and carbon, suspended solids, and phytoplankton. Three phytoplankton groups were modelled based on an analysis of phytoplankton data: cyanobacteria, diatoms and chlorophytes. As discussed in the following sections, the models are in a state of continuous refinement to further enhance their accuracy and reliability as more data becomes available.

Table 1 Data required to run ELCOM-CAEDYM and their sources for SCA reservoirs.

\begin{tabular}{|l|l|}
\hline \multicolumn{1}{|c|}{ Data Required } & \multicolumn{1}{c|}{ Data Source } \\
\hline Bathymetric information & SCA bathymetric surveys \\
\hline Local meteorological conditions & LDSs situated on the reservoirs \\
\hline $\begin{array}{l}\text { Catchment inflow rates, temperature and } \\
\text { conductivity }\end{array}$ & River loggers \\
\hline Pumped transfer inflow rates & SCA database \\
\hline Outflow rates & SCA database \\
\hline Catchment inflow properties & SCA water quality database \\
\hline Pumped inflow properties & SCA routine monitoring data \\
\hline
\end{tabular}

\section{APPLICATION OF SCARMS}

\subsection{Algal Bloom Prediction in Lake Burragorang}

In August 2007 an unexpected algal bloom occurred in Lake Burragorang (refer to Section 2.1) which generated a series of questions relating to evolution of the algal bloom. SCARMS was utilised to assess the historical data record and perform hindcast modelling to gain an understanding of the factors that contributed to the bloom. The model was recalibrated to increase the SCA's capability to forecast similar events in the future and respond quickly to deliver the best available water quality in these events.

The hindcast modelling scenarios indicated that a number of factors contributed to the Microcystis sp. bloom of 2007 (Harris et al., 2011a). A number of large inflows penetrated the reservoir as underflows that lifted up the existing hypolimnion in June 2007. Seasonal and diurnal stratification provided a warm, well-lit environment that was periodically enriched with nutrients via wind mixing events. Microcystis sp. exploited this environment and out-competed other species with their buoyancy regulation that reduces the rate of loss via settling. In the hindcast modelling scenarios, the model captured the magnitude and timing of the 2007 blue-green algae bloom (Figure 3).

Historical modelling provides the ability to assess past events in detail and understand the key processes that contributed to resultant impacts. Where these events can not be captured by the model, the model is recalibrated, or the configuration is adjusted with new knowledge, to develop a tool that is able to predict a greater range of events in the future and therefore enable suitable management actions to be taken.

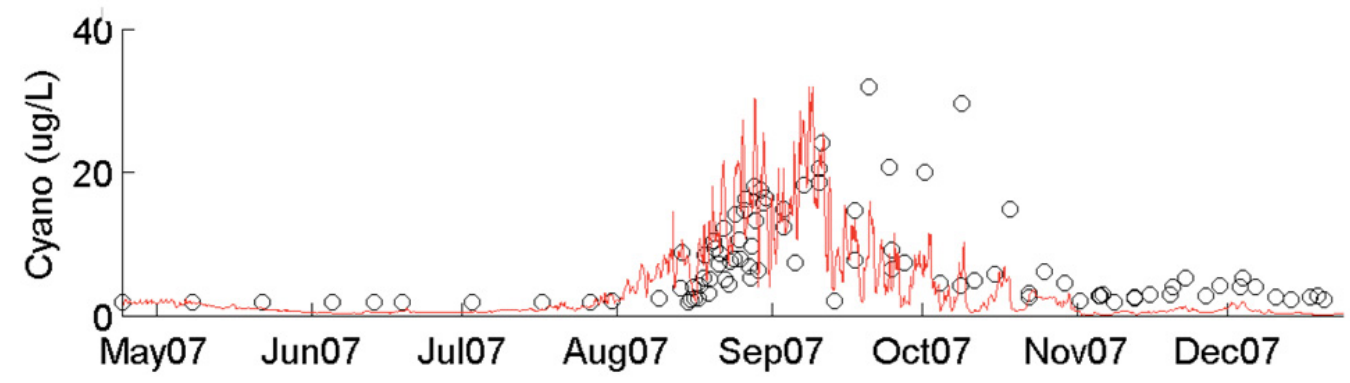

Figure 3. Estimated cyanobacterial concentration from measured cell counts (black points) and simulated cyanobacterial chlorophyll-a concentration (red lines) between 8 May 2007 and 5 January 2008. Source:

Harris et al., 2011a. 
Harris et al., A decision support system for Sydney's water supply.

\subsection{Inflow Transport in Lake Yarrunga}

The application of SCARMS to analyse real-time monitoring data and three-dimensional models allowed the SCA to understand the influence of a series of inflow events, of up to $327 \mathrm{~m}^{3} / \mathrm{s}$ and $162 \mathrm{~m}^{3} / \mathrm{s}$ in the Shoalhaven and Kangaroo River arms of Lake Yarrunga in February 2010. SCARMS was previously calibrated and validated for Lake Yarrunga and was reporting real-time and modelled conditions before, during and after the inflow events of 2010. This provided detailed predictions of the influence of the inflows on the reservoir (Figure 4). The real-time predictions were utilised to provide guidance for a field programme that investigated the dynamics and properties of inflow events in the reservoir using profiling and water quality sample collection (Harris et al., 2011b).

The modelling predicted that the stratified water column would be disrupted by the inflow events, which entered as cool sub-surface intrusions and resulted in the development of a less stratified, three layered water column structure. The zone of interaction of the Shoalhaven and Kangaroo inflows in the central region of the reservoir created an environment of greater water column stability and nutrient elevation. As a result, increased algal growth was predicted in the model in a small patch in the central region of the reservoir. Data collected by the LDSs and the experimental profiling at the simulated patch confirmed the model results. The real-time data collection and modelling was therefore able to provide detailed information on water quality following large inflow events. Applying the DSS prior to, during and after inflow events is critical for the management of transfers through the Shoalhaven scheme to ensure the delivery of the best available water to Lake Burragorang.

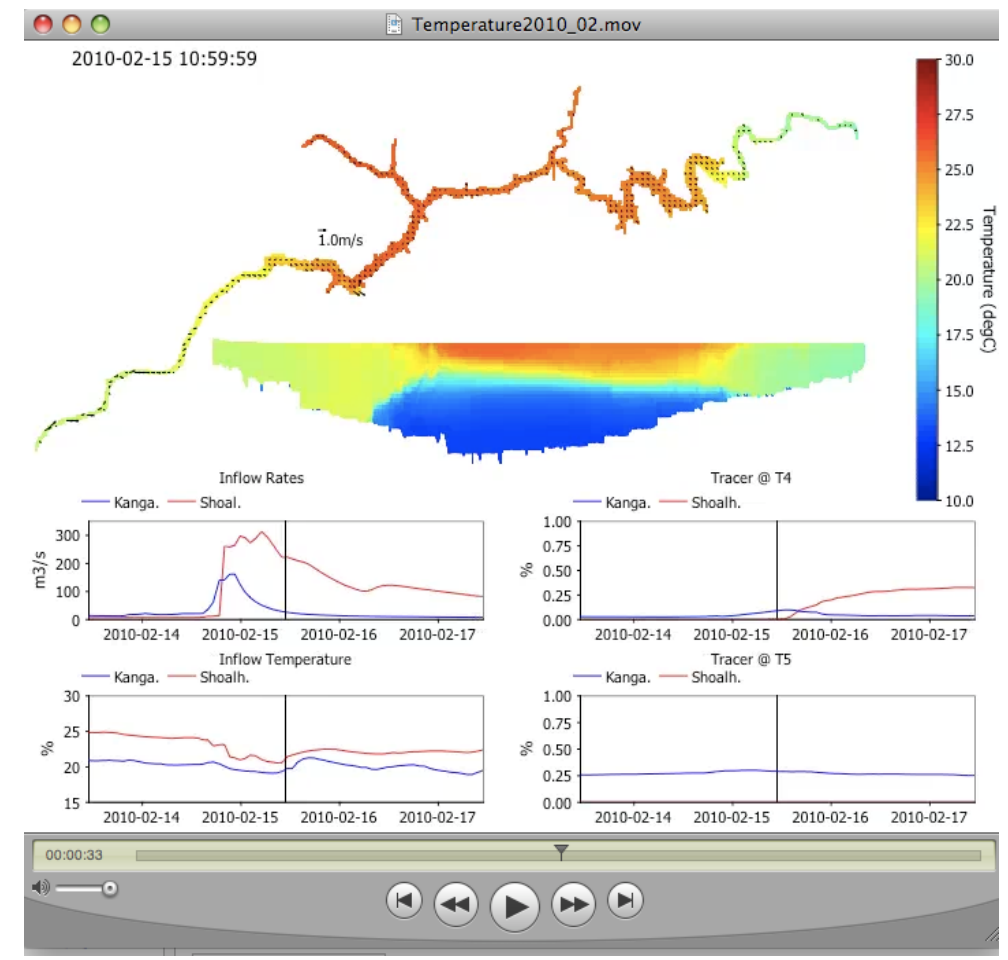

Figure 4. A customized movie generated in SCARMS to show the predicted influence of a series of large inflows and effect on thermal structure of Lake Yarrunga.

\subsection{Daily SCARMS Operation}

SCARMS data are assessed as needed on an ongoing basis and models are running daily for Lake Burragorang, Prospect Reservoir and the three Shoalhaven Reservoirs. Forty-day hindcast simulations are executed each night and model output is compared to the suite of field data on the subsequent day. This provides confidence in the models output for future scenario modelling. The hind-cast runs are used to initialize a range of 'spun up' 10-day future scenarios, including historically large inflow events, no inflow events and recharge/recirculation scenarios. Real-time data and model predictions provide an up-to-theminute report on the conditions in $81 \%$ of the SCA water supply and forecasts of water quality. The daily data and model scenarios provide short-term operational guidance for managing water quality in their 
Harris et al., A decision support system for Sydney's water supply.

supplied water. Alarms and email alerts are configured to alert reservoir managers of potentially undesirable reservoir conditions in future scenarios.

\section{CONCLUSIONS}

SCARMS is an integrated decision support system that integrates field data, knowledge and models from a variety of sources in one framework that supports the management of large-scale water supply in Sydney. SCARMS receives and organises routine and continuous data, performs error checking, down-sampling and visualisation and applies data to drive three dimensional hydrodynamic and water quality modelling and scenario forecasting. The system provides a means for reservoir managers to assess current water quality conditions, key environmental drivers of water quality and forecasted water quality in response to future events. In addition, the system could potentially be used in conjunction with other models and tools to help managers to assess the potential improvement in water quality that may be achieved from a range of management strategies, such as catchment management practices that reduce nutrient loading. The economic and environmental cost of such operational and planning decisions can be identified in advance to optimise resource management.

SCARMS is continuously evolving as new data is obtained and therefore provides a dynamic reservoir management tool and decision support for daily operations and long-term strategic planning. The data, model and knowledge package that forms SCARMS is housed at SCA and demonstrates successful innovations in collating a range of necessary tools into a seamlessly linked and customised decision support system for the management of large-scale water resource systems.

\section{ACKNOWLEDGEMENTS}

Kind acknowledgements to the SCA who provided funding for SCARMS development.

\section{REFERENCES}

Booty, W.G., Lam, D.C.L., Wong, I.W.S. and Siconofli, P., 2001. Design and implementation of an environmental decision support system. Environmental Modelling and Software, 16 (5), 453-458.

Casulli and Cheng, 1992. Semi-implicit finite difference methods for three-dimensional shallow water flow. Int. Journal of Numerical Methods in Fluids, 15, 629-648.

Chung, S.W., Hipsey, M.R., Imberger, J., 2009. Modelling the propogation of turbid density inflows into a stratified lake: Daecheong Reservoir, Korea. Environmental Modelling and Software, 24 (12), 1467-1482.

Ewing, T., Romero, J.R., Imberger, J. Antenucci, J., Deen, A., 2004. A Real-time Reservoir Decision Support System. $6^{\text {th }}$ International Conference on Hydroinformatics.

Harris, J.E., Hillmer, I., Yeates, P.S., 2011a. Lake Burragorang Algal Modelling SCARMS Update. Final Report, May 2011. CWR Document: WP 2324 YH.

Harris, J.E., Marti, C. and Fornarelli, R., 2011b. Extension of SCARMS to the Shoalhaven System. Task 5 \& 6: Experimental Data and Detailed Modelling. Final Report, March 2011. CWR Document WP 2368 JH.

Hipsey, M.R., Antenucci, J.P., Brookes, J.D., Burch, M.D., Regel, R.H., Linder, L., 2004. A three dimensional model of Cryptosporidium dynamics in lakes and reservoirs: A new tool for risk management. International Journal of River Basin Management, 2:3, 181-197.

Hodges B.R., Imberger, J., Saggio A. and Winters, K.B. (2000). Modeling basin-scale internal waves in a stratified lake. Limnology and Oceanography, 45(7): 1603-1620.

Horn, D.A., Gal, G., Yeates, P.S., Imberger, J., Zohary, T., 2002. Water quality modelling for the management of lakes and reservoirs. Proceedings of $32^{\text {nd }}$ International Symposium on Hydraulic Engineering, 3-4 January 2002, Aachen Germany, 201-220.

Vilhena, L.C., Hillmer, I., Imberger, J. 2010. The role of climate change in the occurrence of algal blooms: Lake Burragorang, Australia. 